to determine the various species that are present. As a result, considerable progress has been made on these lines, and during the sixteen years that the Survey has been in existence the number of new species that have been described and of 'types' that have been added to the collections of the Indian Museum has averaged some one hundred and twenty-five a year. Up to quite recent times the Survey has not attempted to deal with purely economic problems, unless specially requested to do so ; it was rightly considered to be of more importance that their energies should be devoted to purely scientific research, for no zoological research can have any economic value unless it has a scientific basis, and the foundation of all such work is taxonomy. Nevertheless, the Survey has from time to time contributed towards the elucidation of problems of economic importance, and has been consulted by various local governments on such problems as the reorganisation of fishery departments, the institution of biological stations, the preservation of the fauna-as, for example, the Monitor lizards that were being exterminated for the supply of skins for the leather market-oyster fisheries, or the control of various species of animals that were directly or indirectly destroying crops. Within the last two years the Survey has by circumstances been compelled to take up one problem of economic importance, namely, the maintenance and preservation of the Trochus and Turbo fisheries in the Andaman Islands.

For many years past, each officer has been encouraged to take up two lines of study-one taxonomic and the other general ; they are thus brought into touch with some of the wider problems of zoology and are in a better position to take advantage of their opportunities for study in the field, while the department as a whole is in a sound position to undertake team-work and thus to tackle the investigation of any of the more general problems, on the solution of which so much may depend in a country like India, in which agriculture and public health are the two subjects of greatest importance.

The Zoological Survey of India publishes the results of its research work in two serials that are devoted to zoology, namely, the Records and Memoirs of the Indian Museum, and within the last year has commenced a third, entitled $A n$ thropological Bulletins from the Laboratory of the Zoological Survey of India. These publications are very largely composed of original papers by the officers of the Survey, and by a system of exchanges with some three hundred other societies and institutions the Survey is able with comparatively little cost to maintain a very fairly complete and up-to-date library, that without any doubt is the finest zoological library for purposes of research in Asia. This library is at the service of every bona fide zoologist throughout the whole of India; a list is kept of all those who are engaged in research work, and every such worker is allowed to have from the library two volumes at a time for a period of a fortnight. In this way workers are able to keep in touch with and consult recent literature, without which it would be impossible for them to carry on their researches. Within the limits imposed on it by space, the Zoological Survey of India also provides accommodation for any research worker who wishes to come to the Museum in order to carry on his work either in the library or in the laboratory, and there is an ever-increasing demand for facilities of this nature, not only from zoologists in India but also from other countries.

It is no exaggeration to say that if the Zoological Survey is in the future to be curtailed, either in its personnel or its financial resources, to such an extent that the continuance of its publications is rendered impossible, such a blow will be dealt to the study of zoology in the whole of India that it will put the country back to where it was in 1875 , when the Museum was first started, and will render almost impossible the satisfactory or trustworthy investigation of every problem in which zoology may be concerned. Finally, any drastic reduction of the staff must seriously endanger the collections. Such collections, especially in a tropical climate, require constant attention for their preservation and continuous study and research to maintain them in an up-to-date and scientific condition, so that each animal is correctly labelled and can at once be referred to for comparison and examination ; and if in the future these collections are allowed to decay, the loss, not to India alone but to the whole world, will be one of the first magnitude.

\title{
Steel in Building Construction
}

$\mathrm{I}^{\mathrm{T}}$ is usual to criticise methods of engineering design by calling the engineer's 'factor of safety' a factor of ignorance. In one sense the accusation is true, since the factor is a cover for uncertainties; but, in effect, it is a concise expression of experience and, properly used, is as legitimate as the apparently more rigorous processes in calculation. It is an inheritance. The efforts of progressive engineers are bent towards its improvement. They attempt the reduction of its margins by enlargement of data, perfection of analysis, and advancement of materials. Sometimes a greater precision in things understood leads to a reduction of the factor, only to disclose the increased importance of things less well understood; and thereby to compel a return. The subject of fatigue in materials and the history of the development of high speed machinery provide numerous examples.

It can scarcely be denied, however, that the factor of safety is subject to serious misuse at times. Weak design methods are frequently characterised by a meticulous arithmetical accuracy in inadequate calculation, covered by an arbitrary factor that may make the design quite safe but certainly renders the careful arithmetic ludicrous. Possibly this charge of imperfect calculation and arbitrary safety factors could be

No. 3258, VoL. 129] 
laid against building structure design. At least, building codes vary so widely that there would appear to be justification for the belief that they reflect a very variable standard in the comprehension of data and of method.

The confusion created by varying codes, in conjunction with a feeling that the full value is not being derived from the use of steel in building structures, and that the highly advanced technique of modern steel structural work is not being fully exploited, has led to a general recognition that comprehensive and systematic investigation is required to obtain precise information and thereby facilitate the establishment of economical design and more uniform regulations. While the recognition of the necessity is widespread, it is gratifying to find that the Department of Scientific and Industrial Research in Great Britain has taken first and bold steps towards this end. The first report, now issued, by the Steel Structures Research Committee,* set up by the Department in 1929 , shows that a wide view has been taken of the task, and that an ambitious programme of research has been undertaken.

The Committee was appointed to review present methods and regulations for the design of steel structures; and to investigate the application of modern theory to such design with a view towards its improvement by the establishment and definition of the data and processes required. The remit would have been more concise and equally comprehensive if it had called for an investigation of all aspects of the 'factor of safety' in steel building structures. The connexion of theory and practice is essentially implied in "factor of safety'. The factor of safety may be nominally modified by extended theory without compelling any important alteration in practice. Theory may advance in completeness, but practice can only be modified by research.

The Committee has very completely realised the true interrelations of established practice, advanced theory, and experimental research; and the programme of work reflects this clearly. But, while understanding the necessity of conducting a full survey of existing methods as a guide to research developments, it has been assumed that the nature of the essential problems would not be greatly altered by the examination of a multiplicity of design systems, while research progress would certainly be impeded. The division of the main lines of work is therefore of the order of an 'intelligent anticipation' of the requirements ; and the Committee has decided upon schemes that embrace such leading items as floor loads, building strains, stress analysis, materials, welded connexions, and building vibration. Good progress appears to have been made with all of these except the last, which, under modern conditions, may ultimately present a restrictive influence on the easy development of more economical design.

The enormous amount of detail work described in the report forbids even a summarised mention

* Department of Scientific and Industrial Research. First Report of the Steel Structures Research Committee. Pp. xii $+276+11$ plates. (London: H.M. Stationery Office, 1931.) 58. net. within this space; but the interest of technical structural engineers will be aroused by the design and tests of the new 'micrometer-microscope' strain gauge and the proposed use of such gauges on the five-story framing of the new Geological Museum at South Kensington, to obtain results for the unloaded frame and as the floors are progressively loaded. There are also most interesting test results on the buckling of I-beam webs, following a request by the British Steelwork Association to have the question of web stiffness examined. In a section on materials, Prof. A. Robertson presents the results of an investigation on the use of small turned specimens in steel testing. These display distinct differences when compared with the yield point results for large flat specimens.

Structural steel framing is of an apparently simple rectangular form, but requires an elaborate theoretical development for its stress analysis. The theory is usually based on the assumption that the joints are rigid. This is not actually the case. The report deals with the general theoretical case of non-rigid connexions briefly; but it is clear that all questions of slip and flexibility at joints require extensive experimental work, as well as theoretical investigation. Both theory and experiment have been employed for riveted, bolted, and welded connexions by Prof. C. Batho, whose results and views are given in a lengthy section of the report.

Laboratory tests on joints alone, however, can scarcely promise to give conclusive information. In actual framing, the mysteries of eccentric loading accompany those of joint flexibility. Calculations given in the report with different assumptions as to eccentricity and joint rigidity show remarkable differences. This appears to have prompted the design of a full scale, threestory, experimental frame which has been erected at the Building Research Station and is to be subjected to extensive experiment when loaded by water tanks. This is perhaps the most notable of the Committee's efforts, and represents an exceptional step in structural research.

A full scale experimental research is always impressive but is, unfortunately, seldom comprehensive. The natural desire is, therefore, to extract the most from the expensive large-size equipment and to endeavour to generalise by the aid of model investigations. The recent American research on arch dams is an excellent example of this procedure. The Committee has also model work in hand, which includes the Beggs deformeter method with celluloid models, and slope measurement methods with others. It is to be hoped that the joint conditions in rectangular framing will not prove too much for small scale models.

The last section of the publication is preceded by the report of the panel dealing with the welding of steel structures, which describes tests of welded joints and outlines a future programme of research upon this mode of construction. Welded connexions are not yet widely adopted and a great deal of investigation will probably be necessary before they become generally acceptable; but 
they offer many advantages, and more precise knowledge and methods of control may overcome the hesitancy of responsible authorities.

The first and last sections of the report are widely apart in position and closely related in theme. The first-which includes in one place an account of a most interesting survey of the real loads on office floors-presents the results of a comparative examination of the regulations controlling steel frame building construction in Great Britain, the Dominions, and in some foreign countries. The general comparison of regulations displays extraordinary variations in such matters as floor loads and wind pressure allowances, and in the clauses governing the proportioning of mem. bers. On practically every page of this section there is evidence of the confusion and variety that can be introduced by autocratic authorities at work independently.

The last part presents the recommendations of the Committee for a code of practice governing the general use of structural steel. In view of the fact that these recommendations accompany a first progress report, there is always the probability of future amendment in the light of subsequent data. It is understood, however, that the code will be explicitly referred to in the model by-laws to be issued by the Ministry of Health. This may be taken as an augury of the full recognition that will be accorded the completed work of so influential and representative a Committee, the first report of which displays a breadth of vision and power of planning that promises ultimate success in a difficult task.

\section{Obituary}

\section{Prof. P. N. Kryloff}

TTHE name of Porphirii Nikitich Kryloff, pro1 fessor of botany and plant geography at the University of Tomsk, who died on Dec. 27, 1931, at the age of eighty-one years, will always be associated with the exploration of the Siberian flora. Born of a poor family, Kryloff had to earn his living ever since he left his school, still a boy in his teens. Becoming an apprentice in a chemist's shop at Perm, young Kryloff became seriously interested in chemistry and medicinal plants, and devoted his spare time to studying for an examination to obtain a pharmacist's degree at the University of Kazan, and to the collection of plants. After obtaining the degree, he continued to work as a dispensing chemist.

The botanical exploration of the Perm province and of the Ural Mountains was now Kryloff's main and only recreation. With very limited resources, often on foot, he wandered over that enormous area, and produced a series of papers on its flora, which was then very little known. In 1874 it became possible for Kryloff to abandon his old profession and to devote himself entirely to botany, by taking a modest appointment as a 'learned gardener ' at the University of Kazan. While at Kazan, he made an extensive study of the flora of that province, but dreamed of botanical explorations in wider and less-known regions.

At the foundation of the new University of Tomsk, the first scientific centre in Siberia, Kryloff did not hesitate to take there the same post of 'learned gardener', becoming later the keeper of the botanical museum, which he built up himself. A new, and practically virgin, field was now open before Kryloff, and he threw himself into this congenial task with his usual energy. Most of western Siberia, the Altai Mountains, and northern Mongolia offered an inexhaustible supply of most interesting problems in the systematics and distribution of plants. An enormous herbarium, comprising more than 200,000 specimens of plants, was the result of the journeys of Kryloff himself and of his students, who were attracted by his unaffected and enthusiastic love of Nature. In systematic studies in the herbarium Kryloff was as thorough as in collecting. He prepared detailed descriptions of all the species known to occur in the regions visited, and maps showing areas of their distribution elsewhere. This formed the basis of his well-known "Flora of Altai and of the Tomsk Province", published in seven volumes between 1901 and 1914. The importance of this work for the study of the flora of temperate Asia and even of Europe cannot be overestimated, and it is not surprising that it was soon out of print.

In 1913 Kryloff was invited to take the post of botanist in charge of the Siberian herbarium at the Academy of Sciences in St. Petersburg but the economic difficulties of living in the capital during the revolution induced him to return in 1917 to Tomsk, where he became professor of botany. Here he set himself a new and a very ambitious task of preparing a complete flora of western Siberia, from the Urals to the Yenisei and from the Arctic Ocean to central Asia. It may seem almost unbelievable, but the work was completed, with the usual masterfulness, within six years, after which several years were spent in endless efforts to find the funds for its publication. It was only in 1926 that the great "Flora of Western Siberia " began to come out in parts, and is still continuing to be published.

Prof. Kryloff's interests were not purely floristic, but mainly phytogeographical, and his exceptional first-hand knowledge of Siberia and its plants enabled him to produce a series of most valuable papers on the distribution and past history of the Siberian flora. One of the points particularly well brought out by Kryloff's work was the existence in the Altai Mountains of an ancient centre of the origin of many typical Siberian plants, which later migrated widely and reached European countries. The foundation of a large and very prolific school of Siberian botanists should be considered amongst the most important achievements of this self-made pioneer of botanical exploration of Siberia.

No. 3258, VoL. 129] 